\title{
Study of fetal doppler velocimetry versus non stress test as predictors of adverse perinatal outcome in high risk pregnancies
}

\author{
K. Hymavathi*, Prasuna P., Davuluru Sandhya Rani
}

Department of Obstetrics and Gynecology, Narayana Medical College and Hospital, Nellore, Andhra Pradesh, India

Received: 02 December 2019

Accepted: 02 January 2020

*Correspondence:

Dr. K. Hymavathi,

E-mail: research.nmch@rediffmail.com

Copyright: (C) the author(s), publisher and licensee Medip Academy. This is an open-access article distributed under the terms of the Creative Commons Attribution Non-Commercial License, which permits unrestricted non-commercial use, distribution, and reproduction in any medium, provided the original work is properly cited.

\section{ABSTRACT}

Background: Pregnancy is a unique, physiologically normal event in a women's life. Objective of this study was to compare the efficacy of the doppler velocimetry versus non stress test in relation to perinatal outcome in high risk pregnancies.

Methods: This is a prospective study conducted in the department of obstetrics and gynaecology, Narayana Medical College and Hospital. 100 women with high risk pregnancy were recruited. All were examined systematically, and Doppler velocimetry and non-stress test were done.

Results: All cases were divided into four groups based on NST and doppler velocimetry of umbilical artery and middle cerebral artery. $10 \%$ of women had abnormal doppler. Middle cerebral artery doppler abnormality was noted in $3 \%$ and CPR abnormality in $3 \%$ of women in the study group. $15 \%$ had abnormal NST. In Group A, out of 88 patients 9 had fetal compromise. In Group B, out of 5 patients all had fetal compromise. In Group C, out of 4 patients none had fetal compromise. In Group D, all 3 patients had fetal compromise. In Group D, all 3 had neonatal deaths. Average birth weights in Group A was $2.7 \mathrm{~kg}$, in Group B was $2 \mathrm{~kg}$, in Group C was $2.5 \mathrm{~kg}$, in Group D was $1.4 \mathrm{~kg}$. Two (2.2\%) newborn in Group A, $4(80 \%)$ newborns in Group B, $3(100 \%)$ in Group had Apgar $<7$ at 5 minutes. 4 $(4.5 \%)$ babies in Group A, $5(100 \%)$ babies in Group B, $3(100 \%)$ babies in Group D were admitted in NICU. Umbilical artery doppler was found to have sensitivity $46.6 \%$, specificity - 94\%, PPV - 93\%, NPV - 54\%. Middle cerebral artery doppler was found to have sensitivity $73.3 \%$, specificity - 90\%, PPV - 91.6\%, NPV- 69.3\%.

Conclusions: In present study, highest percentage of perinatal complications and perinatal deaths were seen in groups with abnormal tests of NST and velocimetry. Group D had the worst perinatal outcome.

Keywords: Doppler velocimetry, High-risk pregnancies, Perinatal complications, Non-stress test

\section{INTRODUCTION}

Pregnancy is a unique, physiologically normal event in a women's life. However, a pre-existing disease or an unexpected illness of the mother or fetus can complicate the pregnancy. High risk pregnancies are a small segment of obstetric population that produces the majority of the maternal and fetal mortality and morbidity. In India, 20$30 \%$ pregnancies belong to high risk category accounting for $80 \%$ of maternal and $75 \%$ of perinatal deaths. ${ }^{1-3}$
The ante partum assessment of fetal well-being has become an integral part of management of both high risk and low risk pregnancies. The goal of various ante partum fetal surveillance techniques is to detect fetal distress so as to prevent fetal morbidity and mortality. The development of a good utero-placental circulation is essential for achievement of a normal outcome of fetus and mother. The largest advances have been made in the assessment of the fetus at risk of hypoxia and death secondary to placental insufficiency. There are numerous 
tests available for this purpose like NST, biophysical profile, modified biophysical profile, doppler velocimetry. With advent of doppler ultrasound it is possible to determine the placental vascular insufficiency early and identify the fetal hemodynamic adaptation to decreased placental blood flow. It is possible to determine the presence of fetal hemodynamic decompensation that resulting in hypoxaemia and acidosis with the help of doppler.

Doppler plays an important role in high risk pregnancies, where haemodynamic rearrangements occur in response to fetal hypoxemia. Doppler findings improve the perinatal outcome in high risk pregnancies, reduces antenatal admissions, induction of labour and caesarean sections for fetal distress. The use of doppler ultrasound for evaluation of the fetal well-being is based on the physical principle of change in frequency of sound wave when it is reflected by blood flow in fetal vessels. The blood vessels most often used for evaluation in pregnancy are mainly umbilical and middle cerebral arteries. Several investigations have tried to establish the applicability of umbilical doppler (excepting absent end diastolic flow) in the prediction of IUGR. There is an increased risk of caesarean section for foetal distress, preterm delivery, neonatal intensive care unit admissions, the need for assisted ventilation and perinatal mortality. Trials have shown that there is a significant decrease in perinatal mortality when evaluation of umbilical artery doppler wave form is included in the management protocols for high risk pregnancies. ${ }^{4}$ Using the combination of arterial and venous doppler testing can result in identification of the majority of fetuses with acidemia (sensitivity 70-90\% and specificity $70-80 \%){ }^{5-7}$

Non stress test is a non-invasive, easily performed, interpreted and readily acceptable by the patient. It is one of the most widely used primary testing methods for antepartum fetal surveillance. NST is a graphical recording of fetal heart rate reactivity to fetal movements. Heart rate accelerations with movements is a reflex that involves the cerebral cortex and is affected by physiological influences like sleep and pathological conditions like fetal hypoxia, which causes variations in heart rate. Non stress test is classified as reactive and non-reactive. Reactive NST is characterized by two or more FHR accelerations of about $15 \mathrm{bpm}$ and lasting at least 15 seconds from the baseline within a 20 minutes period. Non- reactive NST is characterized by lack of accelerations for a period of 40 minutes.

The present study is designed to evaluate fetal doppler velocimetry versus non stress test as predictors of adverse perinatal outcome in high risk pregnancies.

\section{METHODS}

This is a prospective study conducted in the department of obstetrics and gynaecology, Narayana Medical College and Hospital, Nellore for a period of 2 years.
A total 100 women with high risk pregnancies were diagnosed and recruited for the study after informed consent.

\section{Inclusion criteria}

- All women with high risk pregnancies with gestational age $>34$ weeks, with singleton pregnancy

- PIH

- IUGR

- Gestational diabetes

- Oligohydramnios

- Rh negative pregnancy.

\section{Exclusion criteria}

- Women with the following conditions were excluded

- Multiple gestations

- Cardiovascular disease

- Essential hypertension

- Fetus with congenital anomalies.

\section{Patient analysis}

- Detailed history including age, obstetric history and menstrual history were taken

- Gestational age was calculated from the early scan taken before 13 weeks of gestation and from LMP, if menstrual cycles are regular

- Detailed general examination, abdominal examination and local examination were done

- Informed consent was taken and data recorded on the proforma

- Patients were subjected to routine and specific investigations pertaining to associated condition

- Patients were subjected to serial color doppler ultrasonography from 32 weeks of gestation

- $\quad$ Patients were subjected to NST.

\section{Procedure}

The patient was explained about the non-invasive/ atraumatic nature of the procedure. The instrument used was Philips HD 11XE color doppler ultrasound machine with a convex transducer of 2-5 MHz frequency. Doppler wave form was obtained after localizing the vessels by B mode real time scanner. Pulsed doppler was used to get the Doppler signals after localizing the vessels. Doppler examination was done when fetus was in apneic state to avoid the influence of fetal respiration on doppler signals. The signal was recorded for a minimum of 5-8 cycles with blood flow velocity waveforms of equal shape and amplitude and satisfactory quality. Then the image was frozen and measurements were taken. Doppler readings were taken from umbilical artery and middle cerebrel artery. Doppler was obtained at weekly or twice weekly interval depending on the severity. Subsequently NST was performed at least weekly, and even daily in severe cases. NST was done for 20 minutes duration. The test 
was continued for $40 \mathrm{~min}$ in case of non-reassuring status. The patients were followed by serial doppler assessment and non-stress test. Low PI of middle cerebral artery and abnormal uteroplacental ratio indicates brain sparing effect. NST was interpreted according to ACOG criteria. Based on the Doppler and NST study population was divided into four groups; A, B, C, D.

- Group-A: normal NST and normal doppler.

- Group-B: normal NST and abnormal doppler.

- Group-C: abnormal NST and normal doppler.

- Group-D: abnormal NST and abnormal doppler.

The management of pregnancy and route of delivery were based on maternal and fetal parameters.

\section{Identification of various arteries and their criteria}

1. Umbilical artery: Doppler signals were acquired from mid portion of cord. Values of S/D ratio, RI and PI $>95^{\text {th }}$ percentile as per the Harrington et al doppler indices, absent end diastolic velocity (AEDV) and reversed end diastolic velocity (REDV) were considered abnormal.

2. Middle Cerebral Artery (MCA): MCA was visualized in transverse axial view of fetal head at a slightly more caudal plane than the one used for BPD. PI and RI $<5^{\text {th }}$ percentile as per the Harrington et al doppler indices were considered abnormal.

3. Cerebro placental ratio: It is the ratio of Middle cerebral artery PI and Umbilical artery PI. Value less than $5^{\text {th }}$ percentile was considered abnormal. If doppler is normal it was repeated after 2 weeks. In case of abnormal doppler, it was repeated according to the associated risk. The last doppler result before delivery was considered for subsequent correlation of maternal and fetal outcome.

\section{Maternal outcome}

Gestational age at time of delivery and mode of delivery.

\section{Fetal outcome}

Birth weight, Apgar score $<7$ at $5 \mathrm{~min}$, Perinatal morbidity and mortality and NICU admission.

\section{Statistical analysis}

All results are expressed as mean \pm standard deviation, median or range as appropriate. Discrete variables comparison between different groups was done with Chisqare or Fischers exact test. Continuous variables in different groups was compared with Student t-test (for 2 groups) or with one-way analysis of variance (for $>2$ groups). The sensitivity, specificity, positive predictive value, negative predictive value and diagnostic accuracy were determined for all doppler measurements.

\section{RESULTS}

In the present study group, age distribution varied from 18 to 32 years. $56 \%$ of women were in the age group of 21 to 25 years, $28 \%$ of women were in the age group of 26-30 years, $12 \%$ and $4 \%$ of women were in the age group of less than 20 years and more than 30 years respectively. $64 \%$ were primi gravida and $36 \%$ were multi gravida. In the present study, $58 \%$ of women were delivered between 32-36 weeks of gestation and $42 \%$ were between 37-40 weeks of gestation.

Table 1: Maternal high-risk factors.

\begin{tabular}{|c|c|c|c|c|}
\hline $\begin{array}{l}\text { Risk } \\
\text { factors }\end{array}$ & $\begin{array}{l}\text { Group - A } \\
(\mathbf{n}=\mathbf{8 8}) \mathbf{N S T}-\mathbf{N} \\
\text { Doppler - N }\end{array}$ & $\begin{array}{l}\text { Group - B } \\
(\mathrm{n}=5) \mathrm{NST}-\mathbf{N} \\
\text { Doppler }-\mathbf{A b}\end{array}$ & $\begin{array}{l}\text { Group-C } \\
(\mathrm{n}=4) \mathrm{NST}-\mathrm{Ab} \\
\text { Doppler-N }\end{array}$ & $\begin{array}{l}\text { Group-D } \\
(\mathbf{n}=\mathbf{3}) \text { NST-Ab } \\
\text { Doppler -Ab }\end{array}$ \\
\hline PIH & 54 & 4 & 2 & 3 \\
\hline IUGR & 8 & 1 & 2 & 2 \\
\hline Oligo & 12 & 0 & 1 & 0 \\
\hline GDM & 8 & 0 & 2 & 0 \\
\hline Rh-ve & 5 & 0 & 0 & 0 \\
\hline
\end{tabular}

A total $63 \%$ of the women had PIH, 13\% had oligohydramnios, $11 \%$ had IUGR, $10 \%$ had GDM, and $5 \%$ had Rh-negative pregnancy. Normal doppler was noted in $90 \%$ of women and remaining $10 \%$ had abnormal doppler. Normal NST was noted in $85 \%$ of women and remaining $15 \%$ had abnormal NST. umbilical artery indices abnormality were noticed in $10(10 \%)$ women. Out of 10 women $7(70 \%)$ had absent end diastolic flow and 3 had reversal of diastolic flow.
Middle cerebral artery indices abnormality was noted in 3 (3\%) women. 3 (3\%) women had abnormal cerebro placental ratio. $32(32 \%)$ had vaginal delivery and 68 $(68 \%)$ had caesarean section.

In the present study group out of 68 caesarean sections, $16 \%$ women had emergency caesarean section and remaining $52 \%$ women had elective caesarean section. Out of 100 women, $68(68 \%)$ had caesarean section. 
A total $16(23.5 \%)$ had caesarean section for fetal distress, 24(35.3\%) for severe PIH, 13 (19\%) for failed induction, $10(14.7 \%)$ for IUGR, 5 (7\%) for severe oligo.

Group A where both test results were normal, had majority of cases of PIH.

\section{High risk pregnancy - comparison of perinatal outcome}

In the present study, Apgar score $<7$ at 5 minutes were 9, out of these 7 had abnormal doppler velocimetry. In this study average birth weight is low in Group D, where both tests were abnormal. NICU admissions was $4.5 \%$ in Group A and 100\% in Group B and D, where doppler was abnormal. Mean gestational age also low in group D (Table 1).

\section{High risk pregnancy - perinatal mortality}

In the present study, 3 neonatal deaths occur in Group D, highest perinatal mortality and neonatal morbidity were seen in Group D, where both tests were abnormal. Major causes for neonatal deaths were prematurity, respiratory distress syndrome and sepsis (Table 2).

Table 2: High risk pregnancy - perinatal outcome.

\begin{tabular}{|c|c|c|c|c|}
\hline Neonatal characteristics & $\begin{array}{l}\text { Group - A } \\
(\mathbf{n}=\mathbf{8 8}) \text { NST - } \\
\text { N Doppler - N }\end{array}$ & $\begin{array}{l}\text { Group - B } \\
(\mathbf{n}=\mathbf{5}) \text { NST-N } \\
\text { Doppler - Ab }\end{array}$ & $\begin{array}{l}\text { Group-C } \\
(\mathrm{n}=4) \mathrm{NST}-\mathbf{A b} \\
\text { Doppler-N }\end{array}$ & $\begin{array}{l}\text { Group-D } \\
(\mathbf{n}=\mathbf{3}) \mathbf{N S T - A b} \\
\text { Doppler-Ab }\end{array}$ \\
\hline Apgar $<7$ at 5 minutes & 2 & 4 & 0 & 3 \\
\hline Average birth weight & $2.7 \mathrm{~kg}$ & $2 \mathrm{~kg}$ & $2.5 \mathrm{~kg}$ & $1.4 \mathrm{~kg}$ \\
\hline NICU admission & 4 & 5 & 0 & 3 \\
\hline Period of gestation (weeks) & 37 & 35 & 36 & 34 \\
\hline Neonatal deaths & 0 & 0 & 0 & 3 \\
\hline
\end{tabular}

Table 3: Doppler indices - sensitivity and specificity.

\begin{tabular}{|lllllllll|}
\hline & TP & TN & FP & FN & Sensitivity & Specificity & PPV & NPV \\
\hline UA & 14 & 19 & 1 & 16 & 46.6 & 94 & 93 & 54 \\
\hline MCA & 22 & 18 & 2 & 8 & 73.3 & 90 & 91.6 & 69.3 \\
\hline CPR & 26 & 19 & 1 & 4 & 86.6 & 95 & 96.2 & 82.6 \\
\hline
\end{tabular}

\section{Outcome}

In the present study, umbilical artery sensitivity for predicting perinatal morbidity and mortality is 46.6 , specificity is 94 , PPV is 93 and NPV is 54.

Middle cerebral artery sensitivity for predicting perinatal mortality and morbidity is 73.3 , specificity is $90, \mathrm{PPV}$ is 91.6 and NPV is 69.3.

Cerebroplacental ratio sensitivity for predicting perinatal mortality and morbidity is 86.6 , specificity is $95, \mathrm{PPV}$ is 96.2 and NPV is 82.6 (Table 3 ).

\section{DISCUSSION}

High risk pregnancy women warrant a highly sensitive and specific diagnostic test which can be non-invasively applied on a large scale. The traditional methods of fetal surveillance like NST, FHR monitoring and fetal biophysical profile are less reliable, because of their inability to detect early stage of fetal compromise with a significant number of false positive tests and low predictive value.
In the present study group of 100 women with high risk pregnancy, $56 \%$ of women belong to the age group of 21-25 years, which is correlating to the studies done by Malikarjunappa et al (56\%) and Nagar T et al (55\%)., ${ }^{8,9}$ The majority of women in the present study group were primigravidae (64\%). This is close to the studies done by Lakhkar BN et al (60.3\%). ${ }^{10}$ As PIH is more common in primigravidae, there was high incidence of primigravidae in the present study group. Mean gestational age at the time of delivery was 35 weeks in the present study group, which is correlating to the studies done by Rozeta et al (34.8) and Deshmukh A et al (34.4). ${ }^{11,12}$

In the present study group, $\mathrm{PIH}$ was the most prevalent risk factor $(63 \%)$ followed by OLIGO (13\%). PIH was the most prevalent risk factor in other studies like Komuhangi et al $(90 \%) .{ }^{13}$ In the present study, $10 \%$ of women had doppler abnormality, which is correlating to the studies done by Choudhury $\mathrm{N}$ et al $(7 \%) .{ }^{14}$

A total $68 \%$ of women in the current study had caesarean section and it is correlating with studies done by Young Byun JI et al, (69.7\%) and Choudhury $\mathrm{N}$ et al, $(68 \%) .{ }^{14,15}$ 
In the present study group, $23 \%$ of women had emergency caesarean section and this correlates to studies done by Choudhury et al, $(23 \%) .{ }^{14}$ Fetal distress and severe PIH were the contributing factors for emergency caesarean section in the present study group.

A total $16 \%$ of women in current study had emergency caesarean section for fetal distress. This is close to the study done by Choudhury $\mathrm{N}$ et al, $(16 \%) .{ }^{14}$ In present study, mean birth weight was $2.3 \mathrm{~kg}$ and this correlates to the studies done by Sharma U et al $(2.3 \mathrm{~kg})$ and Banshal A et al $(2.3 \mathrm{~kg}) .{ }^{16,17}$

Doppler abnormalities were associated with low birth weight in newborns because of early termination of pregnancies in view of fetal interest and for severe PIH. The lowest birth weight in our study was $1.16 \mathrm{~kg}$ seen in severe PIH women with REDF in doppler. Majority of the babies had good Apgar at birth due to continuous fetal surveillance and timely intervention.

In the present study, $12 \%$ of newborns were admitted in NICU, this is close to study done by Choudhury $\mathrm{N}$ et al, (10\%). Causes for NICU admission were preterm, low birth weight, respiratory distress in present study.

Perinatal mortality was 3\% in this study. This correlates to the study done by Chudhury et al, (3\%).

Most of the perinatal deaths were noted with severe umbilical artery abnormality in the form of absent end diastolic flow and reversal of end diastolic flow.

In present study, AEDF in umbilical artery was seen in $10 \%$ of women which is correlating to the studies done by Prasad GV et al, (6\%) and Manikyrao $\mathrm{S}$ et al, $(10 \%) .^{18,19}$

REDF in umbilical artery is seen in $3 \%$ of women.

The incidence of REDF is less because most of the pregnancies were terminated at or before development of AEDF in umbilical artery. There was only 3 cases with REDF in umbilical artery doppler. It was referred from outside hospital in view of severe pre-eclampsia.

In present study, perinatal mortality in women with AEDF and REDF is $100 \%$, this may be due to severe fetal hypoxia and metabolic acidosis by the time of AEDF and REDF.

In the present study group umbilical artery doppler has specificity is $94 \%$ and PPV is $93 \%$ in predicting adverse perinatal outcome. This correlates to the study done by Khanduri S et al (specificity - 94.4\%, PPV - 96.3\%) and Malik R et al (specificity - 80\%, PPV - 96.6\%). ${ }^{20,21}$

In the present study, middle cerebral artery doppler has specificity of $90 \%$ and PPV of $91.6 \%$ in predicting adverse perinatal outcome. This is close to the studies done by Dhand $\mathrm{H}$ et al.

In present study, cerebroplacental ratio has sensitivity of $86.6 \%$, specificity of $95 \%$ and PPV of $96.2 \%$ in predicting adverse perinatal outcome. This correlates to the studies done by Bano $\mathrm{S}$ et al. ${ }^{22}$

In the present study, cerebroplacental ratio is more sensitive $(86.6 \%)$ and specific $(95 \%)$ in predicting adverse perinatal outcome. Its positive predictive value is $96.2 \%$. This is comparable to the studies done by Malik Rajesh et al (CPR, sensitivity - 68\%, specificity - 100\%, PPV - 100, NPV - 26.3) and Prasad GV et al (CPR, sensitivity - 90, specificity - 88, PPV - 87, NPV - 33.3. It is better predictor of adverse perinatal outcome than umbilical artery or middle cerebral artery alone.

\section{CONCLUSION}

Doppler ultrasound is one such test which is safe, rapid, non-invasive and highly sensitive. It reflects the fetal haemodynamics adequately. Hence, it can be used in the antepartum fetal surveillance along with other tests like NST, modified biophysical profile. AEDF and REDF groups have delivered significantly more preterm and low birth weight babies, compared with the normal doppler group. This suggests that the gestational age of the patient at the time of delivery and the birth weight of the newborn are important factors to influence the neonatal outcome.

NST is mostly widely used test and it reflects oxygenation of brain. Abnormal NST indicates acute hypoxia. NST still holds its importance in fetal monitoring because of its ease of performance and cost effectiveness.

There were no neonatal deaths in Group A, B, C. the normal. Perinatal mortality was highest $(100 \%)$ in Group $\mathrm{D}$ where both tests were abnormal. Perinatal mortality in babies with AEDF and REDF was $100 \%$. Doppler is useful in recognizing fetal compromise earlier than Nonstress test, giving a lead time which is important in the management of preterm high-risk pregnancies. An abnormal NST following abnormal doppler is associated with the worst perinatal outcome. In case with abnormal doppler, if the neonatal survival is good, it is better to deliver the fetus before NST becomes abnormal.

Funding: No funding sources

Conflict of interest: None declared

Ethical approval: The study was approved by the Institutional Ethics Committee

\section{REFERENCES}

1. Deane C, Harrington K. A practical approach to obtaining optimum doppler signals. A colour atlas of 
Doppler ultrasonography in obstetrics. London: Arnold. 1995;168:35-46.

2. Fitzgerald DE, Drumm JE. Non-invasive measurement of human fetal circulation using ultrasound: a new method. BMJ. 1977;2:1450-1.

3. Rao K, Sheshadri S. Fetal doppler. Asian J Obstet Gynecol. 2003;7(7):17-22.

4. Gagnon, Robert, Van den Hof M. The use of fetal Doppler in obstetrics. J Obstet Gynaecol Canada. 2003;25(7):601-14.

5. Baschat AA. Doppler application in the delivery timing of preterm growth-restricted fetus: another step in the right direction. Ultrasound Obstet Gynecol. 2004;23:111-8.

6. Baschat AA, Güclü S, Kush ML, Gembruch U, Weiner CP, Harman CR. Venous doppler in the prediction of acid-base status of growthrestricted fetuses with elevated placental blood flow resistance. Am J Obstet Gynecol. 2004;191:277-84.

7. Rizzo G, Capponi A, Talone PE, Arduini D, Romanini C. Doppler indices from inferior vena cava and ductus venosus in predicting $\mathrm{pH}$ and oxygen tension in umbilical blood at cordocentesis in growth-retarded fetuses. Ultrasound Obstet Gynecol. 1996;7:401-10.

8. Mallikarjunappa B, Harish H, Ashish SR, Pukale RS. Doppler changes in pre-eclampsia. JIMSA. 2013;26:4.

9. Nagar T, Sharma D, Choudhary M, Khoiwal S, Nagar RP, Pandita A. The role of uterine and umbilical arterial doppler in high-risk pregnancy: a prospective observational study from India. Clin Med Insights: Repro Health. 2015;9:CMRH-S24048.

10. Lakhkar BN, Rajagopal KV, Gourisankar PT. Doppler prediction of adverse perinatal outcome in $\mathrm{PIH}$ and IUGR. Indian $\mathbf{J}$ Radiol Imag. 2006;16(1):109.

11. Shahinaj R, Manoku N, Kroi E, Tasha I. The value of the middle cerebral to umbilical artery Doppler ratio in the prediction of neonatal outcome in patient with preeclampsia and gestational hypertension. J Prenatal Med. 2010;4(2):17.

12. Deshmukh A, Soni N, Gokhale S. Significance of umbilical artery doppler velocimetry in the perinatal outcome of the growth restricted fetuses. J Obstet Gynaecol India. 2010;60(1):38-43.

13. Komuhangi P, Byanyima RK, Kiguli-Malwadde E, Nakisige C. Umbilical artery doppler flow patterns in high-risk pregnancy and foetal outcome in Mulago hospital. Case Reports Clin Med. 2013;2(9):554.
14. Choudhury N, Sharma BK, Kanungo BK, Yadav R, Rahman H. Assessment of Doppler velocimetry versus nonstress test in antepartum surveillance of high-risk pregnancy. Int J Repro Contracept Obstet Gynecol. 2017;6(2):664.

15. Byun YJ, Kim HS, Yang JI, Kim JH, Kim HY, Chang SJ. Umbilical artery Doppler study as a predictive marker of perinatal outcome in preterm small for gestational age infants. Yonsei medical journal. 2009;50(1):39-44.

16. Urmila S, Beena B. Triple vessel wave pattern by Doppler studies in normal and high-risk pregnancies and perinatal outcome. J Obstet Gynecol India. 2010;60(4):312-6.

17. Bansal A, Choudhary J, Gupta H. Role of panvessel doppler study in high risk pregnancy. Diabetes. 2015;3:6.

18. Prasad GV, Sarvottam J. Role of doppler study in the evaluation of intrauterine growth retardation. J Evi Med Healthcare. 2015;2(42):7266-75.

19. Manikyarao S, Baby Indira N, Gayathri S. Role of colour doppler in pregnancy induced hypertension; Indian J Applied Res. 2015;5(4).

20. Khanduri S, Parashari UC, Bashir S, Bhadury S, Bansal A. Comparison of diagnostic efficacy of umbilical artery and middle cerebral artery waveform with color Doppler study for detection of intrauterine growth restriction. The $\mathrm{J}$ Obstet Gynecol India. 2013;63(4):249-55.

21. Rajesh M, Agamya S. Role of colour doppler indices in the diagnosis of intrauterine growth retardation in high- risk pregnancies. The J Obst Gynec India 2013;63(1):37-44.

22. Bano S, Chaudhary V, Pande S, Mehta VL, Sharma AK. Color doppler evaluation of cerebral-umbilical pulsatility ratio and its usefulness in the diagnosis of intrauterine growth retardation and prediction of adverse perinatal outcome. Indian $\mathbf{J}$ Radiol Imag. 2010;20(1):20

Cite this article as: Hymavathi $\mathrm{K}$, Prasuna $\mathrm{P}$, Davuluru SR. Study of fetal doppler velocimetry versus non stress test as predictors of adverse perinatal outcome in high risk pregnancies. Int $\mathbf{J}$ Reprod Contracept Obstet Gynecol 2020;9:729-34. 